\title{
Humanističke transformacije u predavanju Ilije Crijevića o Properciju
}

\author{
Neven Jovanović \\ Odsjek za klasičnu filologiju \\ Filozofski fakultet Sveučilišta u Zagrebu \\ neven.jovanovic@ffzg.unizg.hr
}

30. rujna 2021.

\begin{abstract}
Sažetak
Jedno je od četiri sačuvanih filološko-retoričkih djela Ilije Crijevića predavanje o Properciju, Praelectio in explicationem elegiarum Propertii (oko 1500?). Analizom sadržaja, citata i izvora tog humanističkog uvodnog predavanja pokazat ću otvorene i skrivene postupke Crijevićevih kulturnih transfera i transformacija. Sferu referencije predavanja čini niz istaknutih autora - Platon, Auzonije, Klaudijan, Silije Italik, Ciceron; Filippo Beroaldo Stariji (1453-1505), Angelo Poliziano (1454-1494), Michele Marullo (1458-1500); pritom suvremenici u predavanju ostaju »skriveni«: korišteni, ali ne i imenovani. Crijevićeva retorička filologija i filološka retorika virtuozan su individualni primjer pristupa koji zapažamo širom renesansne Dalmacije.
\end{abstract}

\section{Primjer humanističkog uvodnog predavanja, izvođe- nog na početku nastave}

Zbirka humanističkih uvodnih predavanja: K. Müllner, Reden und Briefe Italienischer Humanisten, Wien 1899: Giovanni Argiropulo, Gasparino Barzizza, Filippo Beroaldo, Lodovico Carbone, Cristoforo Landino, Lappo da Castiglionchio, Ognibene Bonisoli, Francesco Filelfo, Sicco Polenton i dr. 


\section{Teme: pjesništvo, moral i estetika}

\section{Recepcija u djelu: horizontalna i vertikalna}

1. Vertikalni ili dijakronijski transfer: filološka asimilacija antike, povezivanje podataka o djelima i ljudima

2. Horizontalni ili sinkronijski: filološka asimilacija rada suvremenih filologa

\section{Primjer transfera}

Plerique mortalium caste ac pudice magis loqui quam uiuere student, ut Crispum Sallustium fecisse memoriae proditum est et illos, de quibus eleganter dictum est: qui Curios simulant et Bacchanalia uiuunt. Poetae uero longe secus faciunt, qui materiam laetiorem, uitam sanctiorem sequuntur. Hinc illud Catulli:

Nam castum esse decet pium poetam

Ipsum, uersiculos nihil necesse est;

Qui tum denique habent salem et leporem

Si sunt molliculi ac parum pudici.

Hinc etiam Adrianus imperator Voconio poetae decenter inscripsit: „Lasciuus uersu, mente pudicus erat. " Nec minus et probatissimo uiro Plinio tribuit Ausonius poeta, quod nos apud Martialem reperimus: »Lasciua est nobis pagina, uita proba est, „ quod uterque ab Ovidio mutuati sunt, quod scribit ad Augustum:

Crede mihi mores distant a carmine nostro:

Vita verecunda est, Musa iocosa mea est.

Ov. Trist. 2, $353-354$

Quid ipsius Augusti dicam in uita seueritatem, in uersibus nullam uerborum uerecundiam? Quid Sulpitii mores de carmine non spectandos? Quid Calvi, Tycidae, Memmii, Cinnae, Anseris, Cornificii, Catonis, Metelli, Hortensii, Cecinnae et Galli et Tibulli et Ouidii, quorum non ex libris, in quibus multa capiendis auribus confinguntur, sed ex moribus et honesta uoluntate uitam pensitauit antiquitas? Quid Epicurum citra malos mores, utpote parce et sobrie uiuentem, in praeceptis praua et inhonesta disserentem? Quid Apuleium in uita philosophum, ad Cerelliam obscaena quaedam et impudica scribentem? Quid Fesceninam locutionem, quid Crothopegnion? Quid mimmos obscaena iocantes, quid comicos, quid Menandrum, quid ipsum Terentium et cum eo Scipionem et Laelium, grauissimos uiros, leuia et ludicra et meretricia ioculariter 
dictantes? Quid Parthenien a uerecundia dictum, qui non solum coitus regum et deorum sed etiam brutorum per admissarios et gregis maritos decenter immiscuit? Quid alia vel obscaena in libris illis, quae tamen nihil illius uitam dehonestant? Quid ipsum Platonem, seuerissimum hominem, quem deum unicum philosophorum plaerique dicunt, in ephoebos ioculariter suos amores professum? Hinc illud de Agathone, quod nos ita uertimus:

Suavia dum uelox Agathonis in oscula migrat

Vix anima est labris aegra recenta meis.

Eadem de Socratis amoribus dici possunt: num tamen aut Socratis aut Platonis integerrimos amores ex ludicris rebus infamabimus?

\subsection{Philippi Beroaldi oratio habita in principio enarrationis Pro- pertii continens laudes amoris (1491)}

Ceterum cum ille qui deum colit amet et sacerdotes; nos, qui amoris cultores esse uolumus, diligamus illius sacerdotes. Qui profecto sunt poetae amasii atque elegiographi, quorum lepidiora poemata non sunt spernenda neque pro argumento impudiciciae sunt habenda; et quamuis uetus uerbum sit talem esse hominum uitam qualis sit oratio, tamen poetis ludere uersiculis amatoriis et lasciuire permittitur. Nam, ut inquit Catulus,

Castum esse decet pium poetam

Ipsum: uersiculos nihil necesse est.

Qui tum denique habent salem, et leporem

Si sunt molliculi ac parum pudici.

Quod autem amatoria scripta nullum prebeant specimen morum nullumque sint uitae turpis inditium, testatur Adrianus imperator, qui Voconii poetae tumulum uersibus exornans ita scripsit: »lasciuus uersu mente pudicus eras «; et ab Ouidio decenter et uere dictum est:

Crede mihi mores distant a carmine nostro.

Vita uerecunda est: musa iocosa mihi.

Ouidio subscribit festiuissimus poeta epigrammaticus de se ipso scribens: „Lasciua est nobis pagina. Vita proba est. “ Quid autem poetarum exempla commemoro? cum seuerissimi sanctissimique philosophorum ludicros amatoriosque uersiculos conscripserint: qui tanto sanctiores existimantur quanto apertiores. (...) Denique audite uel unicum dei philosophorum Platonis exemplum, qui uersiculis huiusmodi amores suos non erubuit profiteri; Latine ita possumus interpretari: 
Suauia dans Agathoni, Animam ipse in labra tenebam.

Egra etenim properans tanquam abitura fuit.

Ex hisne quaeso uersiculis parum pudicis Platonem impudicum existimabimus Platonisque mores infamabimus? qui tantum abfuit ab impudicicia quantum uersiculi a pudicicia; cuius uita tanto probatior fuit quanto musa lasciuior.

\subsection{Ausonius (310-395) 18, 4 / Cento nuptialis, epilogus (Veneci- ja: Tacuinus, 14. X. 1496)}

Sed cum legeris, adesto mihi adversum eos, qui, ut Iuvenalis ait, „Curios simulant et Bacchanalia vivunt «, ne fortasse mores meos spectent de carmine. "Lasciva est nobis pagina, vita proba ", ut Plinius dicit. Meminerint autem, quippe eruditi, probatissimo viro Plinio in poematis lasciviam, in moribus constitisse censuram, prurire opusculum Sulpitii, nec frontem caperare, esse Apuleium in vita philosophum, inepti grammatis amatorem, in praeceptis omnibus exstare severitatem, in epistulis ad Cerelliam subesse petulantiam, Platonis Symposion composita in ephebos epyllia continere. Nam quid Anniani Fescenninos, quid antiquissimi poetae Lemnii crothopegnion libros loquar? Quid euentum, quem Menander sapientem vocavit? Quid ipsum Menandrum? Quid comicos omnes? Quibus severa vita est et laeta materia. Quid etiam Parthenien dictum causa pudoris, qui VIII Aeneidos, cum describeret coitum Veneris atque

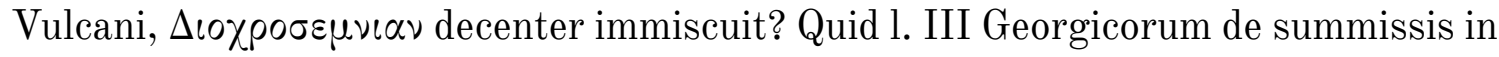
gregem maritis nonne obscenam significationem honesta verborum translatione velavit? Et si quid in nostro ioco aliquorum hominum seueritas uestita condemnat: de Virgilio accersitum sciat.

\subsection{Ovidius, Tristia 2, 427-448}

Sic sua lasciuo cantata est saepe Catullo

Femina, cui falsum Lesbia nomen erat;

Nec contentus ea, multos uulgauit amores,

In quibus ipse suum fassus adulterium est.

Par fuit exigui similisque licentia Calui,

Detexit uariis qui sua furta modis.

Cinna quoque his comes est, Cinnaque procacior Anser,

Et leue Cornufici parque Catonis opus.

Quid referam Ticidae, quid Memmi carmen, apud quos

Rebus adest nomen nominibusque pudor, 
Et quorum libris modo dissimulata Perilla est,

Nomine nunc legitur dicta, Metelle, tuo?

Is quoque, Phasiacas Argon qui duxit in undas,

Non potuit Veneris furta tacere suae.

Nec minus Hortensi, nec sunt minus improba Serui

Carmina. quis dubitet nomina tanta sequi?

Vertit Aristiden Sisenna, nec offuit illi,

Historiae turpis inseruisse iocos.

Non fuit opprobrio celebrasse Lycorida Gallo,

Sed linguam nimio non tenuisse mero.

Credere iuranti durum putat esse Tibullus,

Sic etiam de se quod neget illa uiro...

\section{Zaključak i perspektive}

Crijevićevu predavanju o Properciju pristupili smo iz dva smjera. Jedan se svojedobno zvao Quellenforschung: njegov je cilj identificiranje izvora kojima se autor koristio. Zadovoljimo li se činom identifikacije, ostat će dojam da je književno djelo recikliranje drugog književnog djela. Pomak s »istraživanja izvora - gdje su preuzete komponente važnije od onoga što se s njima u djelu događa - ka istraživanju transformacije kao postupka kulturne mijene obavezuje nas da promislimo ne samo odakle Crijević crpi, nego što čini s odabranim tuđim riječima i idejama; kako iz tuđeg teksta odabire, kako premješta i proširuje.

Slično je s drugim smjerom pristupa. Dok je u tradicionalnom shvaćanju kulturnih veza nacionalne književne povijesti bitno posvjedočiti da se »stranci“ dive "našima ", a da naši dokazuju da drže korak sa »svijetom «, uvid koji izbjegava anakronizam - uvid koji ne traži u prošlosti legitimaciju sadašnjosti - usmjerava našu pozornost na postupke kojima se ostvaruju kulturne veze: je li to suradnja u istraživanju ili pisanje popratnih tekstova, primanje tuđih tekstova ili njihovo poticanje, reagiranje na tuđi rad i njegova preoblika. Od konstatacije da veze postoje zanimljivije je $k a-$ ko se ostvaruju. Takva dinamičnija mreža, koja osim povezanih točaka određuje i narav njihovih veza, omogućuje nam da razmišljamo kakvih veza ima, a kakvih nema. Ona može dovesti, vjerujem, do drugačijeg pogleda na dalmatinski renesansni humanizam. 